\title{
Nilai Ekologis Ekosistem Hutan Mangrove
}

\author{
Siti Julaikha ${ }^{1}$, Lita Sumiyati ${ }^{1}$ \\ ${ }^{1}$ Mahasiswa Program Studi Magister Pendidikan IPA Universitas Mataram \\ Email : julaikha@gmail.com
}

\begin{abstract}
Abstrak
Mangrove mempunyai peranan nilai ekologis yang sangat penting dalam mendukung konservasi laut dan pembangunan wilayah pesisir. Fungsi dan manfaat mangrove telah banyak diketahui, baik sebagai tempat pemijahan ikan di perairan, pelindung daratan dari abrasi oleh ombak, pelindung daratan dari tiupan angin, penyaring intrusi air laut ke daratan dan kandungan logam berat yang berbahaya bagi kehidupan, tempat singgah migrasi burung, dan sebagai habitat satwa liar serta manfaat langsung lainnya bagi manusia. Teknik pengumpulan data dalam panelitian ini yaitu studi kepustakaan, yang merupakan suatu teknik pengumpulan data dengan menghimpun dan menganalisis dokumen-dokumen, baik dokumen tertulis, gambar ataupun elektronik, dalam hal ini berupa analisis artikel dari berbagai sumber jurnal (Internasional \& Nasional) kemudian dianalisis secara deskriptif.
\end{abstract}

kata kunci: Ekologis, Ekosistem, dan Hutan Mangrove.

\begin{abstract}
Mangrove has a very important ecological value role in supporting marine conservation and coastal area development. The functions and benefits of mangroves have been widely known, both as a spawning ground for fish in waters, land protection from abrasion by waves, land-covering from the wind, intrusion of seawater into land and heavy metal contents harmful to life, bird migration shelter, and as a wildlife habitat as well as other direct benefits to humans. The technique of collecting data in this research is literature study, which is a technique of collecting data by collecting and analyzing documents, either written documents, drawings or electronic, in this case in the form of article analysis from various sources of journals (International \& National) then analyzed in descriptive.
\end{abstract}

Keywords: Ecological, Ecosystem, and Mangrove Forest. 


\section{Pendahuluan}

Hutan mangrove adalah tipe hutan yang khas terdapat di sepanjang pantai atau muara sungai yang dipengaruhi oleh pasang surut air laut.Mangrove tumbuh pada pantaipantai yang terlindung atau pantai-pantai yang datar, biasanya di sepanjang sisi pulau yang terlindung dari angin atau di belakang terumbu karang di lepas pantai yang terlindung (Nontji, 1987; Nybakken, 1992).

Ekosistem hutan mangrove bersifat kompleks dan dinamis, namun labil. Dikatakan kompleks karena ekosistemnya di samping dipenuhi oleh vegetasi mangrove, juga merupakan habitat berbagai satwa dan biota perairan.Jenis tanah yang berada di bawahnya termasuk tanah perkembangan muda (saline young soil) yang mempunyai kandungan liat yang tinggi dengan nilai kejenuhan basa dan kapasitas tukar kation yang tinggi.Kandungan bahan organik, total nitrogen, dan ammonium termasuk kategori sedang pada bagian yang dekat laut dan tinggi pada bagian arah daratan (Kusmana, 1994).

Saat ini luas hutan mangrove di dunia adalah sekitar 17 juta ha (ISME, 1991), yang mana sekitar 3,7 juta ha $(22 \%$ IURS areal) terdapat di Indonesia (Soerianegara dan Kusmana, 1993). Akibat pesatnya laju aktivitas pembangunan di berbagai sektor dan laju pertambahan penduduk, terutama di negaranegara sedang berkembang di daerah tropika, di masa datang luas hutan mangrove diduga akan semakin menyusut. Walaupun peranan penting hutan mangrove dalam ekosistem pantai sudah diketahui secara luas, namun pemanfaatan hutan mangrove (khususnya di negara-negara sedang berkernbang) berjalan dengan tidak berlandaskan pada informasi (data) ilmiah yang bersifat komprehensif, sehingga banyak hutan mangrove menurun kualitasnya bahkan hilang sama sekali. Oleh karena itu, masalah yang sangat penting sehubungan dengan hutan mangrove adalah ketidakterarahan dan kelangkaan data (Kusmana, 1993; Burbridge dan Koesoebiono, 1980).

Sebagai daerah peralihan antara laut dan darat, ekosistem mangrove mempunyai gradien sifat lingkungan yang tajam.Pasang surut air laut menyebabkan terjadinya fluktuasi beberapa faktor lingkungan yang besar, terutama suhu dan salinitas.Oleh karena itu, jenis-jenis tumbuhan dan binatang yang memiliki toleransi yang besar terhadap perubahan ekstrim faktorfaktor tersebutlah yang dapat bertahan dan berkembang. Kenyataan ini menyebabkan keanekaragaman jenis biota mangrove kecil, akan tetapi kepadatan populasi masingmasing umumnya besar (Kartawinata et al., 1979). Karena berada di perbatasan antara darat dan laut, maka hutan mangrove merupakan ekosistem yang rumit dan mempunyai kaitan, baik dengan ekosistem darat maupun lepas pantai. Mangrove di Indonesia mempunyai keragaman jenis yang tinggi yaitu memiliki 89 jenis tumbuhan yang terdiri dari 35 jenis pohon, 5 jenis terna, 9 jenis perdu, 9 jenis liana, 29 jenis epifit, dan 2 jenis parasit (Nontji, 1987).

Untuk menjamin kelestarian produksi \&an fungsi ekologi ekosistem hutan mangrove, rangkaian penelitian ekologi hutan mangrove sangat diperlukan karena data ekologi merupakan data dasar untuk pengelolaan sumberdaya secara 
lestari. Hal ini di sebabkan karena tanpa pengetahuan ekologi, aksi-aksi pengelolaan sumberdaya tidak hanya terbatas, tetapi juga kurang efisien dan efektif. Oleh karena itu untuk kepentingan pengelolaan sumberdaya mangrove yang berkelanjutan, suatu program penelitian ekologi hutan mangrove yang bersifat komprehensif sangat diperlukan.

\section{Bahan dan Metode}

Teknik yang dilakukan untuk mengumpulkan data pada dalam panelitian ini yaitu melakukan studi kepustakaan, yang merupakan suatu teknik pengumpulan data dengan menghimpun dan menganalisis dokumen-dokumen, baik dokumen tertulis, gambar ataupun elektronik, dalam hal ini berupa analisis artikel dari berbagai sumber jurnal (Internasional \& Nasional) dengan menggunakan kata kunci Ekologis, Ekosistem, dan Hutan Mangrove.Analisis data dilakukan secara deskriptif.

\section{A. Keterangan Global, Ekosistem Hutan}

\section{Mangrove}

Batasan Hutan Mangrove Kata mangrove merupakan kombinasi antara bahasa Portugis mangue dan bahasa Inggis grove (Macnae, 1968). Dalam bahasa Inwis kata mangrovedigunakan baik untuk komunitas tumbuhan yang tumbuh di daerah jangkauan pasang- surut maupun untuk individu-individu species tumbuhan yang menyusun komunitas tersebut. Sedangkan dalam bahasaPortugis kata mangrove digunakan untuk menyatakan individu species tumbuhan, sedangkan kata mangal untuk menyatakan komunitas tumbuhan mangrove tersebut. Saat ini, pengertian mangrove yang berasal dari bahasa Inggrislah yang banyak digunakan oleh kalangan para peneliti dan pemerhati mangrove bahkan oleh khalayak umum. Dengan demikian hutan mangrove adalah hutan yang dipengaruhi oleh pasang-surut air laut. Pengertian mangrove berkembang terus dari waktu ke waktu, sehingga dewasa ini yang dimaksud dengan sumberdaya mangrove adalah (Saenger et al,1983):

1. Satu atau lebih tumbuhan khas mangrove (exlusive mangrove) yang hanya tumbuh di habitat mangrove,

2. Satu atau lebih tumbuhan yang berasosinsi dengan tumbuhan khas mangrove, tetapi tumbuhan tersebut hidupnya tidak terbatas di mangrove,

3. Biota (hewan) darat clan laut yang berasosiasi dengan habitat mangrove; dan

4. Berbagai proses esensial yang berperan penting dalarn memelihara kelestarian fungsi hutan mangrove.

\section{B. Sifat Viviparitas Dan Sistem Perakaran}

Beberaps species mangrove memperlihatkan sifat viviparitas (biji sudah berkecambah selagi buah masih menernpel pada ranting). Semua anggota dari suku Rhizophoraceae, Avicennin sp. (Verbenaceac), dan Aegiceros corniculatum(Myrsinaceae) memperlihatkan vivipritas ini. Menurut Chapman (1975), terdapat tujuh sistem perakaran utama mangrove, yaitu :

1. Sistem perakaran sederhana yang timbul tenggelam dalam tanah, Lumnitzera $s p$,

2. Sistem akar lutut, misal Bruguera spp., 
3. Akar dorsal yang tumbuh ke atas yang bertumpu pada akar horizontal, misal Catnptostetnon spp.,

4. Sistem perakaran horizontal yang berupa banir, misal Xylocarpus spp.,

5. Akar pasak, misal Avicennia spp.,

6. Akar pasak yang memproduksi pnemathoda terminal, misal Laguncltlnria sp.; dan

7. Akar tunjang, misal Rhizosphora spp.

\section{Kondisi Mangrove Saat Ini}

Kondisi Umum di Indonesia Tekanan yang berlebihan terhadap kawasan hutan mangrove untuk berbagai kepentingan tanpa mengindahkan kaidah-kaidah pelestarian alam telah mengakibatkan terjadinya penurunan luas hutan mangrove yang cukup drastis. Berdasarkan data tahun 1984, Indonesia memiliki mangrove dalam kawasan hutan seluas 4,25 juta ha, kemudian berdasar hasil interpretasi citra landsat (1992) luasnya tersisa 3,812 juta ha (Ditjen INTAG dalam Martodiwirjo, 1994); dan berdasarkan data Ditjen RRL (1999), luas hutan mangrove Indonesia tinggal 9,2 juta ha (3,7 juta ha dalam kawasan hutan dan 5,5 juta ha di luar kawasan). Namun demikian, lebih dari setengah hutan mangrove yang ada $(57,6 \%)$, ternyata dalam kondisi rusak parah, di antaranya 1,6 juta ha dalam kawasan hutan dan 3,7 juta ha di luar kawasan hutan. Kecepatan kerusakan mangrove mencapai 530.000 ha/th. Upaya merehabilitasi daerah pesisir pantai dengan penanaman jenis mangrove sebenarnya sudah dimulai sejak tahun sembilanpuluhan.Data penanaman mangrove oleh Departemen Kehutanan selama tahun 1999 hingga 2003 baru terealisasi seluas 7.890 ha
(Departemen Kehutanan, 2004), namun tingkat keberhasilannya masih sangat rendah.Data ini menunjukkan laju rehabilitasi hutan mangrove hanya sekitar 1.973 ha/tahun.Di samping itu, masyarakat juga tidak sepenuhnya terlibat dalam upaya rehabilitasi mangrove, dan bahkan dilaporkan adanya kecenderungan gangguan terhadap tanaman mengingat perbedaan kepentingan.

\section{PERANAN EKOLOGIS MANGROVE}

\section{A. Mangrove dan Tsunami}

Fungsi dan manfaat mangrove telah banyak diketahui, baik sebagai tempat pemijahan ikan di perairan, pelindung daratan dari abrasi oleh ombak, pelindung daratan dari tiupan angin, penyaring intrusi air laut ke daratan dan kandungan logam berat yang berbahaya bagi kehidupan, tempat singgah migrasi burung, dan sebagai habitat satwa liar serta manfaat langsung lainnya bagi manusia. Musibah gempa dan ombak besar tsunami yang melanda Nanggroe Aceh Darussalam (NAD) dan Pulau Nias akhir tahun 2004 yang lalu telah mengingatkan kembali betapa pentingnya mangrove dan hutan pantai bagi perlindungan pantai. Berdasar karakteristik wilayahnya, pantai di sekitar kota Padang pun masih merupakan alur yang sama sebagai alur rawan gempa tsunami.

Dilaporkan bahwa pada wilayah yang memiliki mangrove dan hutan pantai relatif baik, cenderung kurang terkena dampak gelombang tersebut. Hasil penelitian menunjukkan bahwa ketebalan mangrove selebar $200 \mathrm{~m}$ dengan kerapatan 30 pohon/100 $\mathrm{m}^{2}$ dengan diameter batang 15 $\mathrm{cm}$ dapat meredam sekitar 50\% energi 
gelombang tsunami (Harada dan Fumihiko, 2003 dalam Diposaptono, 2005). Gelombang laut setinggi 1,09 m di Teluk Grajagan, Banyuwangi dengan energi gelombang sebesar 1.493,33 Joule tereduksi gelombangnya oleh hutan mangrove menjadi 0,73 m (Pratikno et al., 2002).

Hasil penelitian Istiyanto et al. (2003) yang merupakan pengujian model di laboratorium antara lain menyimpulkan bahwa rumpun bakau (Rhizophora spp.) memantulkan, meneruskan, dan menyerap energi gelombang tsunami yang diwujudkan dalam perubahan tinggi gelombang tsunami melalui rumpun tersebut. Hasil-hasil tersebut menunjukkan bahwa keberadaan mangrove di sepanjang pantai dapat memperkecil efek gelombang tsunami yang menerjang pantai. Mazda dan Wolanski (1997) serta Mazda dan Magi (1997) menambahkan bahwa vegetasi mangrove, terutama perakarannya dapat meredam energi gelombang dengan cara menurunkan tinggi gelombang saat melalui mangrove.

\section{B. Mangrove dan Sedimentasi}

Hutan mangrove mampu mengikat sedimen yang terlarut dari sungai dan memperkecil erosi atau abrasi pantai.Erosi di pantai Marunda, Jakarta yang tidak bermangrove selama dua bulan mencapai 2 $\mathrm{m}$, sementara yang berbakau hanya $1 \mathrm{~m}$ (Sediadi, 1991). Dalam kaitannya dengan kecepatan pengendapan tanah di hutan mangrove, Anwar (1998) dengan mengambil lokasi penelitian di Suwung Bali dan Gili Sulat Lombok, menginformasikan laju akumulasi tanah adalah $20,6 \mathrm{~kg} / \mathrm{m}^{2} /$ th atau setara dengan $14,7 \mathrm{~mm} / \mathrm{th}$ (dominasi Sonneratia alba); $9,0 \mathrm{~kg} / \mathrm{m}^{2} /$ th atau 6,4 $\mathrm{mm} / \mathrm{th}$ (dominasi Rhizophora apiculata); 6,0 $\mathrm{kg} / \mathrm{m}^{2} /$ th atau $4,3 \mathrm{~mm} / \mathrm{th}$ (bekas tambak); dan $8,5 \mathrm{~kg} / \mathrm{m}^{2} /$ th atau $6,0 \mathrm{~mm} / \mathrm{th}$ (mangrove campuran). Dengan demikian, rata-rata akumulasi tanah pada mangrove Suwung $12,6 \mathrm{~kg} / \mathrm{m}^{2} / \mathrm{th}$ atau $9 \mathrm{~mm} / \mathrm{th}$, sedang mangrove Gili Sulat $8,5 \mathrm{~kg} / \mathrm{m}^{2} /$ th atau 6,0 $\mathrm{mm} / \mathrm{th}$. Data lain menunjukkan adanya kecenderungan terjadinya pengendapan tanah setebal antara 6 sampai $15 \mathrm{~mm} / \mathrm{ha} / \mathrm{th}$ atas kehadiran mangrove. Informasi semacam ini sangat diperlukan guna mengantisipasi permasalahan sosial atas lahan timbul di kemudian hari.

\section{Mangrove dan Siklus Hara}

Penelitian tentang gugur daun telah cukup banyak dilakukan. Hasil pengamatan produksi serasah di Talidendang Besar, Sumatera Timur oleh Kusmana et al. (1995) menunjukkan bahwa jenis Bruguierra parviflora sebesar $1.267 \mathrm{~g} / \mathrm{m}^{2} / \mathrm{th}, \quad$ B. sexangula $1.269 \mathrm{~g} / \mathrm{m}^{2} / \mathrm{th}$, dan $1.096 \mathrm{~g} / \mathrm{m}^{2} / \mathrm{th}$ untuk komunitas B. sexangula-Nypa fruticans. Pengamatan Khairijon (1999) di hutan mangrove Pangkalan Batang, Bengkalis, Riau, menghasilkan 5,87 $\mathrm{g} / 0,25 \mathrm{~m}^{2} /$ minggu daun dan ranting $\mathrm{R}$. mucronata atau setara dengan $1.221 \mathrm{~g} / \mathrm{m}^{2} / \mathrm{th}$ dan $2,30 \mathrm{~g} / 0,25 \mathrm{~m}^{2} / \mathrm{minggu}$ daun dan ranting Avicennia marina atau setara dengan 478,4 $\mathrm{g} / \mathrm{m}^{2} / \mathrm{th}$, dan cenderung membesar ke arah garis pantai. Hasil pengamatan Halidah (2000) di Sinjai, Sulawesi Selatan menginformasi-kan adanya perbedaan produksi serasah berdasar usia tanamannya. R. mucronata 8 tahun $(12,75$ ton/ha/th $)$, kemudian 10 tahun (11,68 ton/ha/th), dan 9 tahun $(10,09$ ton/ha/th $)$, dengan laju pelapukan 74\%/60 hr (tegakan 8 th); 96\%/60 
hr (tegakan 9 th), dan 96,5\%/60 hr (tegakan 10 th). Hasil pengamatan di luar pun memperoleh data produksi berkisar antara 517 ton daun kering/ha/th (Bunt, 1978; Sasekumar dan Loi, 1983; Boonruang, 1984; dan Leach dan Burkin, 1985). Sukardjo (1995) menambahkan hasil pengamatan guguran serasahnya sebesar 13,08 ton/ha/th, yang setara dengan penyumbangan $2 \mathrm{~kg}$ $\mathrm{P} /$ ha/th dan $148 \mathrm{~kg} \mathrm{~N} / \mathrm{ha} /$ th. Nilai ini sangat berarti bagi sumbangan unsur hara bagi flora dan fauna yang hidup di derah tersebut maupun kaitannya dengan perputaran hara dalam ekosistem mangrove. D. Mangrove dan Produktivitas Perikanan Kebijakan pemerintah dalam menggalakkan komoditi ekspor udang, telah turut andil dalam merubah sistem pertambakan yang ada dalam wilayah kawasan hutan. Empang parit yang semula digarap oleh penggarap tambak petani setempat, berangsur beralih "kepemilikannya" ke pemilik modal, serta merubah menjadi tambak intensif yang tidak berhutan lagi (Bratamihardja, 1991). Ketentuan jalur hijau dengan lebar $130 \mathrm{x}$ nilai rata-rata perbedaan pasang tertinggi dan terendah tahunan (Keppres No. 32/1990) berangsur terabaikan.

\section{Mangrove dan Intrusi Air Laut}

Mangrove juga mampu dalam menekan laju intrusi air laut ke arah daratan.Hasil penelitian Sukresno dan Anwar (1999) terhadap air sumur pada berbagai jarak dari pantai menggambarkan bahwa kondisi air pada jarak $1 \mathrm{~km}$ untuk wilayah Pemalang dan Jepara dengan kondisi mangrove-nya yang relatif baik, masih tergolong baik, sementara pada wilayah Semarang dan Pekalongan, Jawa Tengah sudah terintrusi pada jarak $1 \mathrm{~km}$.

Tabel 1. Keanekaragaman jenis tumbuhan mangrove di beberapa negara

\begin{tabular}{lcl}
\hline No. Negara & Jumlah jenis & \multicolumn{1}{c}{ Pustaka } \\
\hline 1. Indonesia & 101 & Kusmana (1993a) \\
2. Malaysia (Matang) & 30 & Chan (1989) \\
3. Thailand & 92 & Aksornkoea (1993) \\
4. Burma & 48 & $\begin{array}{l}\text { Myint and } \\
\text { Soe (1985) }\end{array}$ \\
5. Vietnam & & Ross (1975) \\
6. Filipina & 40 & Arroyo (1979) \\
7. Papua New Guinea & 78 & $\begin{array}{l}\text { Paijman and } \\
\text { Rollet (1977) }\end{array}$ \\
8. Brunei Darussalam & 49 & Salleh and \\
9. Queensland & & De Silva (1989) \\
& Wells (1983) \\
10. Fustralia) & 33 & Peng and \\
11. Kyusu (Jepang) & & Xin Men (1983) \\
12. Victoria (Australia) & 1 & Nakasuga (1979) \\
13. Selandia Baru & 1 & Wells (1983) \\
14. Fijapman (1983) & & Walting (1986) \\
\hline
\end{tabular}

\section{E. Mangrove dan Keanekaragaman \\ Hayati}

Mangrove juga memiliki fungsi ekologis sebagai habitat berbagai jenis satwa liar.Keanekaragaman fauna di hutan mangrove cukup tinggi, secara garis besar dapat dibagi dua kelompok, yaitu fauna akuatik seperti ikan, udang, kerang, dan lainnya serta kelompok terestrial seperti insekta, reptilia, amphibia, mamalia, dan burung (Nirarita et al., 996).

Hutan mangrove juga sebagai habitat beberapa jenis burung yang dilindungi seperti pecuk ular (Anhinga melanogaster), bintayung (Freagata andrewsi), kuntul perak kecil (Egretta garzetta), kowak merah (Nycticorax caledonicus), bangau tongtong (Leptoptilos javanicus), ibis hitam (Plegadis falcinellus), bangau hitam (Ciconia 
episcopus), burung duit (Vanellus indicus), trinil tutul (Tringa guitifer), blekek asia (Limnodromus semipalmatus), gegajahan besar (Numenius arquata), dan trulek lidi (Himantopus himantopus) (Sutedja dan Indrabrata, 1992). Jenis-jenis burung Egretta eulophotes, kuntul perak (E. intermedia), kuntul putih besar (E. alba), bluwok (Ibis cinereus), dan cangak laut (Ardea sumatrana) juga mencari makan di dekat hutan mangrove (Whitten et al., 1988).

Tahel 2. Keanekaragaman jenis fauna laut ekosistem mangrove di beberapa negara

\begin{tabular}{lcl}
\hline No. Negata & Jumlah jenis & \multicolumn{1}{c}{ Pustaka } \\
\hline 1. Indonesia & 118 & Soemodihardjo et al. (1993) \\
2. Malaysia & 54 & Chong et al. (1990) \\
3. Thailand & 62 & Paphavasit and \\
(Phuket) & & Setti (1981) \\
4. Fiji & 70 & Lal et al. (1984) \\
\hline
\end{tabular}

\section{F. Mangrove dan Produktivitas Perikanan}

Kebijakan pemerintah dalam menggalakkan komoditi ekspor udang, telah turut andil dalam merubah sistem pertambakan yang ada dalam wilayah kawasan hutan. Empang parit yang semula digarap oleh penggarap tambak petani setempat, berangsur beralih "kepemilikannya" ke pemilik modal, serta merubah menjadi tambak intensif yang tidak berhutan lagi (Bratamihardja, 1991). Ketentuan jalur hijau dengan lebar $130 \mathrm{x}$ nilai rata-rata perbedaan pasang tertinggi dan terendah tahunan (Keppres No. 32/1990) berangsur terabaikan.
Hasil penelitian Martosubroto dan Naamin (1979) dalam Dit.Bina Pesisir (2004) menunjukkan adanya hubungan yang signifikan antara luasan kawasan mangrove dengan produksi perikanan budidaya. Semakin meningkatnya luasan kawasan mangrove maka produksi perikanan pun turut meningkat dengan membentuk persamaan $\mathrm{Y}=0,06+0,15 \mathrm{X} ; \mathrm{Y}$ merupakan produksi tangkapan dalam ton/th, sedangkan $\mathrm{X}$ merupakan luasan mangrove dalam ha.

Hasil penelitian lain yang berkaitan dengan ekonomi menunjukkan bahwa pembuatan 1 ha tambak ikan pada hutan mangrove alam akan menghasilkan ikan/udang sebayak $287 \mathrm{~kg} / \mathrm{tahun}$, namun dengan hilangnya setiap 1 ha hutan mangrove akan mengakibatkan kerugian 480 $\mathrm{kg}$ ikan dan udang di lepas pantai per tahunnya (Turner, 1977).

\section{G.Mangrove dan Kesehatan}

Rusminarto et al. (1984) dalam pengamatannya di areal hutan mangrove di Tanjung Karawang menjumpai 9 jenis nyamuk yang berada di areal tersebut.Dilaporkan bahwa nyamuk Anopheles sp., nyamuk jenis vektor penyakit malaria, ternyata makin meningkat populasinya seiring dengan makin terbukanya pertambakan dalam areal mangrove.

Hal ini kemungkinan meningkatnya penularan malaria dengan makin terbukanya areal-areal pertambakan perikanan. Kajian lain yang berkaitan dengan polutan, dilaporkan oleh Gunawan dan Anwar (2005) yang menemukan bahwa tambak tanpa mangrove mengandung bahan pencemar berbahaya merkuri (Hg) 16 kali lebih tinggi 
dari perairan hutan mangrove alami dan 14 kali lebih tinggi dari tambak yang masih bermangrove (silvofishery). Saat ini sedang diteliti, di mana kandungan merkuri diserap (pohon mangrove, biota dasar perairan, atau pun ikan).

\section{Kesimpulan Dan Saran}

Mangrove mempunyai peranan nilai ekologis yang sangat penting dalam mendukung konservasi laut dan pembangunan wilayah pesisir. Oleh karena itu, kegiatan rehabilitasi menjadi sangat prioritas sebelum dampak negatif dari hilangnya mangrove ini meluas dan tidak dapat diatasi (tsunami, abrasi, intrusi, pencemaran, dan penyebaran penyakit).

Dalam merehabilitasi mangrove seluas 18.405 ha areal mangrove disuatu daerah yang diperlukan adalah master plan yang disusun berdasarkan data obyektif kondisi biofisik dan sosial.Untuk keperluan ini, Pusat Litbang Hutan dan Konservasi Alam dapat memberikan kontribusi dalam penyusunan master plan dan studi kelayakannya.Dalam hal rehabilitasi mangrove, ketentuan green belt perlu dipenuhi agar ekosistem mangrove yang terbangun dapat memberikan fungsinya secara optimal (mengantisipasi bencana tsunami, peningkatan produktivitas ikan tangkapan serta penyerapan polutan perairan).

\section{Daftar Pustaka}

Aksornokea.1993. Mangrove Of Thailand: Present Status Of Conservation Use and Management. 83-133
Anwar, C. 2005. Wanamina, Alternatif Pengelolaan Kawasan Mangrove Berbasis Masyarakat. Prosiding Ekspose Hasil Penelitian Pemanfaatan Jasa Hutan dan Non Kayu Berbasis Masyarakat sebagai Solusi Peningkatan Produktivitas dan Pelestarian Hutan, Cisarua, 12 Desember 2003: 21-26.

Bratamihardja, H. M. 1991. Pengelolaan Hutan Payau di Pantai Utara Pulau Jawa. Prosidings Seminar IV, Ekosistem Mangrove, Bandar Lampung, 7- 9 Agustus 1990: 59-63.

Bratamihardja, H. M. 1991. Pengelolaan Hutan Payau di Pantai Utara Pulau Jawa. Prosidings Seminar IV, Ekosistem Mangrove, Bandar Lampung, 7- 9 Agustus 1990: 59-63. Program MAB Indonesia - LIPI. Jakarta.

Chiril. A., Gunawan. H. 2007. Peranan ekologis dan social ekonomis hutan mangrove dalam mendukung pembangunan wilayah pesisir. Prosiding Ekspose Hasil-Hasil Penelitian, 2007

Departemen Kehutanan. 2004 Statistik Kehutanan Indonesia, Frorestry Statistics of Indonesia 2003. Badan Planologi Kehutanan, Departemen Kehutanan, Jakarta.

Gunawan, H. 2000. Desentralisasi : Ancaman dan Harapan Bagi Masyarakat Adat (Studi Kasus Masyarakat Adat Cerekang di Kabupaten Luwu Timur, Provinsi Sulawesi Selatan). CIFOR. Bogor.

Istiyanto, D.C., S.K. Utomo, dan Suranto. 2003. Pengaruh Rumpun Bakau terhadap Perambatan Tsunami di Pantai. Makalah pada Seminar Nasional "Mengurangi Dampak 
Tsunami: Kemungkinan Penerapan Hasil Riset" di Yogyakarta, 11 Maret 2003.

Kusuma, C. 1996. Nilai Ekologis Ekosistem Hutan Mangrove (Ecological Values of Mangrove Forest Ecosystem). Media Konservasi Vol. V No. (I), April 1996 : $17-24$

Nirarita, C.E., P. Wibowo dan D. Padmawinata (eds). 1996. Ekosistem Lahan Basah Indonesia. Kerjasama antara Wetland International Indonesia Programme, Ditjen PHPA, Canada Fund, Pusat Pengembangan Penataran Guru Ilmu Pengetahuan Alam dan British Petrolium. Jakarta.

Poedjirahajoe, E. 2000.Pengaruh Pola Sylvofishery terhadap Pertambahan Berat Ikan Bandeng (Canos canos Forskal) di Kawasan Mangrove Pantai Utara Kabupaten Brebes. Jurnal Konservasi Kehutanan, Vol. 2, Agustus 2000: 109-124, UGM, Yogyakarta.

Program MAB Indonesia - LIPI. Jakarta. Bunt, J.S. 1978.The Mangrove of the Eastern Coast of Cape York Peninsula of Cooktown. Great Barrier Reef Mar. Park Author Working Paper No. 1:253269.

Pusat Litbang Hutan dan Konservasi Alam, Bogor Boonruang, P. 1984.The Rate of Degradation of Mangrove Leaves, Rhizophora apiculata BL and Avicennia marina at Phuket Island, Western Peninsular of Thailand. Proc. As. Symp. Mangr.Env.Research and Management (ed. E. Soepadmo, A.N. Rao; D.J. Macintosh), Kualalumpur, June 1984: 200-208.

Rusminarto, S., A. Munif, dan B. Riyadi. 1984. Survey Pendahuluan Fauna
Nyamuk di Sekitar Hutan Mangrove Tanjung Karawang, Jawa Barat. Prosiding Seminar II: Ekosistem Mangrove: 232-234. LIPI, Balai Penelitian Hutan, Perum Perhutani, Biotrop dan Dit. Bina Program Kehutanan, Jakarta.

Saenger, P., EJ. Hengert. 1983. Global Status Of Magrove ecosystems. IUCN.Comision ON Ekology. Number 3

Sasekumar, A. and J. J. Loi. 1983. Litter Production in Three Mangrove ForestZones in Malay Peninsula. Aqu. Bot. 17: 283-290.

Whitten, A.J., M. Mustafa dan G.S. Henderson. 1988. The Ecology of Sulawesi. Gadjah Mada University Press.Yogyakarta.

Wirjodarmodjo, H. dan Z. Hamzah.1982. Beberapa Pengalaman Perum Perhutani dalam Pengelolaan Hutan Mangrove. Prosiding Seminar II: Ekosistem Mangrove: 29-40. LIPI, Balai Penelitian Hutan, Perum Perhutani, Biotrop, Dit. Bina Program Kehutanan, Jakarta 